\title{
两系法杂交稻母本变异的原因 及对策探讨
}

薛光行

(中国农业科学院作物育种栽培研究所. 北京 100081)

摘要 两系法杂交水稻现有母本一一光敏雄性核不育系变异得不仅比常规品种快, 甚至比“三 系稻”的母本还要快, 阻碍该项技术应有潜力的发挥. 介绍“两系稻”现有母本的遗传变异性过 强的现象, 分析了其成因, 并对进一步纯化其光敏性与温敏性的育种策略做了初步探讨.

\section{关键词 两系法杂交水稻 雄性核不育系 光敏性 温敏性 育种对策}

由我国首创的两系法杂交水稻( 以下简称“两系稻”) 技术采用光敏雄性核不育系作母本, 由于母本的雄性不育性受细胞核隐性基因控制, 恢复谱广 ${ }^{[1,2]}$, 所以它比三系法杂交水稻有进 一步提高稻谷产量与品质的潜力; 然而母本雄性育性的表现还受光敏性、温敏性和栽培环境的 光-温周期条件支配. 因此“两系稻”的生产易受异常气象条件干扰 ${ }^{[3]}$. 探索降低生产风险的育 种新措施, 是该项技术研究的关键. 借助于袁隆平 ${ }^{[4]}$ 和卢兴桂 ${ }^{[5]}$ 提出的育种策略, “两系稻”于 1993 年进入中试阶段. 然而, 中试实践显示: ( ) 制种时现有母本常出现部分可育的变异株, 导致杂交种纯度不高 ${ }^{[5]} ;($ ) 湖南、湖北、广西和安徽等省已通过技术鉴定的不育系仍发生不 育临界温度及生育期的分离, 随着繁殖世代数的增加异型株剧增 ${ }^{[6]} ;()$ 袁隆平提出不育系 提纯和原种生产程序 ${ }^{[7]}$, 按照该程序在 $24{ }^{\circ} \mathrm{C}$ 提纯所得表现完全雄性不育的“核心”单株, 其自 交后代在同样温度下仍分离出部分可育株 ${ }^{[8,9]}$, “含杂量” (变异) 高达 $18 \%{ }^{[10]}$; ( ) 由育

的情况则仅能看到分布松散的线或环位错, 未出现非晶(参见图 2(b)). 以上实验事实说明了 较重离子注入时, 由复杂的, 稳定的损伤结构形成波导边界区, 有利于克服一般轻离子注入时 形成波导势垒的隧道效应, 更适合制备永久性的, 非渗漏型和低光损耗的光波导. 同时有关微 结构的观测结果也支持了文献[3] 所用 $6.0 \mathrm{MeV} \mathrm{B}$ 离子, $1 \times 10^{15} \mathrm{~cm}^{-2}$ 剂量注入 $\mathrm{KN}$ 晶体得到了 非渗漏型光波导特性的结果.

致谢＼cjkstart本工作为核工业科学基金(编号: H7196FY003) 资助项目.

\section{参 考 文 献}

1 Townsend P D. An overview of ion_implanted optical waveguide profiles. Nucl Inst Meth, 1990, B46: 18 25

2 Fluck D, Irmscher R, Buchal Ch, et al. Tailoring of optical planar waveguides in $\mathrm{KNbO}_{3}$ by $\mathrm{MeV} \mathrm{He}$ ion implantation. Ferroelectrics, 1992, 128: $79 \sim 84$

3 Xia Zonghuang, Li Yan, Shen Dingyu, et al. Formation of optical waveguides in $\mathrm{KNbO}_{3}$ by $\mathrm{MeV}$ boron ion implantation. Nucl Inst Meth, 1997, B122: 253 254 
种家提供的“核心种子”或原原种充其量只可扩繁 2 次 ${ }^{[7,11,12]}$ 。扩繁次数虽然少, 不育系种子 生产和制种生产的风险却仍然比较高. 总之, 不育系植株的光、温敏性不一致 ${ }^{[13]}$, 遗传变异性 过强, 阻碍着“两系稻”技术潜力的发挥. 而且, 现行的提纯措施“治标不治本”[9]. 本文探讨其 原因及育种对策, 希望能促进问题的早日解决.

\section{1 “两系稻”母本遗传变异性过强的原因}

遗传变异性是繁殖群体的普遍特征. 绝大多数新培育成的品种仍有剩余的杂合基因位 点, 因重组而引起后代的分离本是司空见惯之事. 但是为什么“两系稻” 母本的遗传变异性比 常规品种和“三系稻”的不育系都强? 为什么混杂得过快?

\section{1 光敏性和温敏性的遗传行为十分复杂}

“光敏性”与“温敏性” 或“感光性”与“感温性”, 都是关于植物发育对栽培环境光-温周期 条件应答 (或响应) 能力的表述, 英文都是“Photosensitivity and Thermosensitivity”; 区别在它们分 别支配或影响雄性育性表达或茎端分化两个不同发育阶段的光周期作用与温周期作用.

研究感光性与感温性的文献数以万计, 然而, 由于感光性和感温性所支配或影响的是既连 贯又相对独立的一系列生理学、生物化学过程中的某一个(或一些) 过程, 其中每一过程的每一 步骤都受一组或几组基因的控制, 涉及的基因数目众多 ${ }^{[14]}$, 表现型受多种光温互作方式的调 控 ${ }^{15,16]}$, 并受基因选择性表达的影响 ${ }^{[17]}$, 增加了遗传学研究的难度. 所以, 有关其遗传行为如 今仍知之甚少 ${ }^{[18]}$.

光敏性与温敏性也同样复杂, 只是研究尚少, 知之也更少. 目前仅知道: 它们的遗传基础 不同, 是与雄性核不育性独立遗传的性状 ${ }^{[19]}$; 根据农垦 $58 \mathrm{~s}$ 与农垦 58 品种相比 PHYA 基因表 达活性较高 ${ }^{[20]}$, 推断光敏性的遗传至少与光敏色素基因簇有关; 根据它们同时具有 $\mathrm{PE}$ (光周 期效应指数值)、诱导败育临界日长 $\left(\mathrm{SD}_{x}\right)$ 与完全不育临界日长 $\left(\mathrm{LD}_{x}\right)$ 、光敏温度区间、不育临 界温度、TE (温周期效应指数值) 等多种表现型 ${ }^{[21]}$, 涉及 20 多种 物质变化或生命过程 ${ }^{8,22]}$, 而 且在分离群体中个体 PE 和 TE 的频率分布皆为连续分布, TE 为单峰连续分布 ${ }^{[19]}$, 推断光敏性 与温敏性属于多基因性状. 基因之间及基因与环境之间的互作, 增加了准确识别期望基因型 的难度. 因为雄性核不育系的育种需要选择的性状很多, 除农艺性状、开花习性、生育期、感光 性、配合力和雄性不育性之外, 还包括光敏性与温敏性, 对其中任一性状的选择效率都很低, 比 常规育种低而且比三系稻不育系的育种还要低. 所以, 即使人工选择是完全正确的, 经十几代 选择后, 有关光敏性和温敏性仍然可能存在着较多的剩余杂合位点 ${ }^{[9]}$.

\section{2 人工选择不够完善}

受有关光敏性与温敏性基础生物学研究深度的制约, 人工选择并不完善. “两系稻”中试 之前如此 ${ }^{[4]}$, 中试启动以后也同样如此.

不少研究者忽略了育性表达的数量特征, 尤其忽略了光敏雄性核不育水稻有两个临界日 长值 - $\mathrm{LD}_{x}$ 与 $\mathrm{SD}_{x}$, 两值相差 1 个多小时, 在两值之间雄性败育度随日照的延长而线性增 加 ${ }^{[3]}$, 即光周期效应指数值 (PE) 急剧增大、响应强度急剧增加以及光敏性与温敏性互作、属于 多基因性状的特点, 误以为雄性育性对光周期条件的变化只表现“不应答”或“应答” ${ }^{[23,24]}$ 。受 此观点支配, 绝大多数有关育性转换现象的研究局限于考察几种恒定温度或日平均温度与光 周期应答的关系, 推测光周期应答的温度阈值和温度区间; 有关光温互作的认识也拘泥于温度 
对不育临界日长值的修饰, 满足于以温度阈值为核心的育性转换光温作用模式 ${ }^{[4]}$; 而对于在光 敏温度区间内依然存在的温周期应答与光周期应答的互作关系、两种应答的应答量 - $\mathrm{TE}$ 和 $\mathrm{PE}$ 变异、遗传的行为以及根据 $\mathrm{TE}$ 与 $\mathrm{PE}$ 的集成类型识别温敏性与光敏性互作基因型的研 究 ${ }^{[19,25,26]}$ 不够重视. 所以, 现行的人工选择程序包括不育系的提纯程序, 都未能超出袁隆平 和卢兴桂的设计 ${ }^{[4,5]}$, 缺乏对光敏性和温敏性的多种表现型、尤其对敏感性强度的有针对性的 选择, 导致现有不育系植株光敏性与温敏性的集成类型不一致. 图 1 是对光敏不育系农艮 $58 \mathrm{~s}$ 的百株样本实测的结果. 由每个点的坐标 $\{\mathrm{PE}, \mathrm{TE}\}$ 可判断植株光敏性与温敏性的互作类型, 由坐标点的散布情况可见其分离.

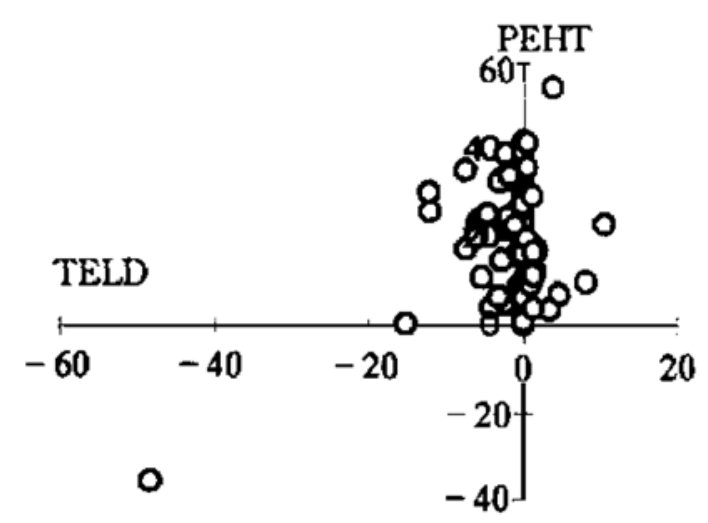

PELT

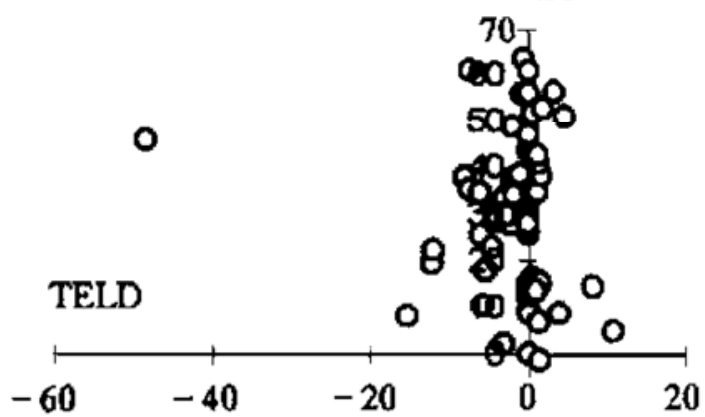

PELT

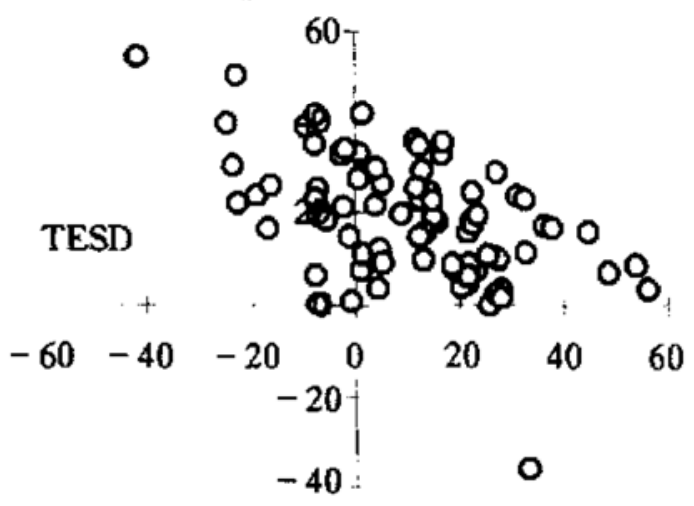

PEHT

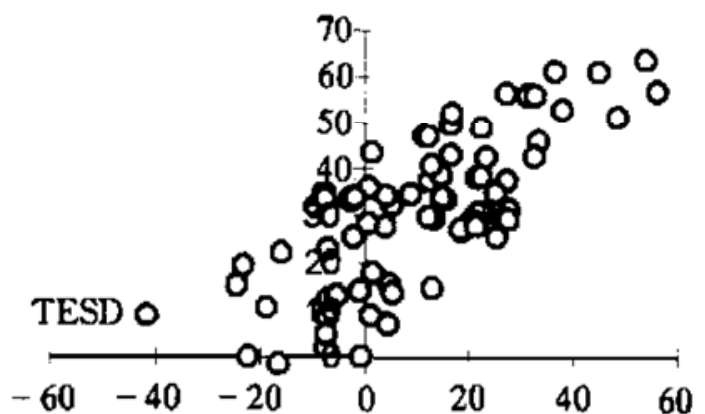

图 1 农垦 $58 \mathrm{~s}$ 雄性不育植株光敏性与温敏性互作类型的多样性

\section{3 自然选择推波助澜}

自然选择的法则是适者生存. 与普通的隐性核不育性相比, 光敏核不育性因为有光敏性 和温敏性, 较易繁衍, 而广泛存在. 自然选择是朝着光- 温敏感性较强尤其温敏性较强、较易 发生育性转换、从而不育性较不稳定的方向进行的. 然而, 育种家为了确保制种的纯度, 则千 方百计地朝着不育性能够稳定表达的方向选择. 以图 1 为例, 育种家希望不育系植株的坐标 $\{\mathrm{PE}, \mathrm{TE}\}$ 都集中在第 1 象限, 而且都集中在靠近纵坐标轴的某个极小的范围之内; 而自然选择 则立图突破这一范围, 使坐标点散布开来, 散布到同一象限远离纵坐标轴的地方, 甚至散布到 其他象限. 何况“两系稻”现有的母本本身已经包藏着不少温敏性较强的变异株, 使自然选择 更加有机可乘, 异型株在较难繁殖的不育系内蔓延使不育系很快便变得面目全非.

总之, “两系稻”现有母本遗传变异性过于强的客观原因是颇难准确识别光敏性与温敏性 的期望基因型, 而且, 因为人工选择与自然选择矛盾尖锐、育种成果易遭受自然选择的破坏; 其 
人为的原因是受有关光-温敏性研究及认识深度的局限, 缺乏对光敏性、温敏性的强度及其互 作类型的人工选择.

\section{2 进一步纯化“两系稻”母本的光敏性与温敏性}

推广“两系稻”函待进一步纯化现有不育系的光敏性与温敏性, 应当努力探讨人工选择的 新思路和新方法. 结合自己的研究实践, 本文提出如下 3 点建议.

\section{1 把待纯化的不育系双单倍体化, 提高潜在遗传变异的外显率}

所谓“双单倍体” (DH) 化, 就是把普通二倍体变为纯合加倍单倍体( doubled haploid)．具体 做法是收集待纯化不育系的花药作为外植体, 通过组织培养获得再生单倍体, 经过染色体加倍 并对农艺性状和倍性作选择, 获得再生二倍体植株群体. 因为这些植株多是同质二倍体, 原来 在普通二倍体中处于杂合状态的基因在这里通通变为纯合, 所以,既能够提高潜在遗传变异的 外显率, 从而提高育种家识别期望基因型的准确性, 也能够大幅度地减少入选后代的分离.

本课题组 1997 年完成了我国最重要的 2 个雄性核不育系——农垦 $58 \mathrm{~s}$ 和培矮 $64 \mathrm{~s}$ 的 DH 化, 并分别获得了有百株规模的 DH 植株群体. 初步的栽培和观察显示: ( ) DH 化没有导致 植株生长势的显著减弱; ( ) DH 群体分别保持着供体不育系育性转换的群体特征, 包括图 1 所显示的遗传变异性.

\section{2 以选择 PE 与 TE 集成类型为中心, 对多种表现型实施综合选择}

周广洽考察过 100 余份雄性核不育材料, 发现它们的不育临界温度只相差约 $2{ }^{\circ} \mathrm{C}^{[8]}$. 据此 不难想象, 同一不育系不同植株的不育临界温度差距将十分微妙, 人工气候室的控温精度将限 制育种家对不育临界温度做更精细的选择. 鉴于图 1 所显示的分离情况, 本文建议实施以 PE 与 TE 集成类型为中心的、对光敏性和温敏性多种表现型的综合选择. 具体做法是: ( ) 把待 纯化不育系的 DH 植株编号, 通过剥分藍把植株逐一一分为四, 相同编号的蕉茎分别栽培在按 光周期、温度两因子、两水平设置的 4 间人工气候室栽培. PE 或 TE 分别等于相同温度(或光 周期) 下长日照植株与短日照植株(或高温植株与低温植株) 的花粉不育度或小穗不育率之差. 根据 1 次实验便可测得每一参试植株的 PEHT, PELT, TELD 和 TESD, 即高温或低温下的 PE 值 和长日照或短日照下的 TE 值. ( ) 人工气候室光周期、温度水平的设置隐含了对不育临界 温度、温度区间和不育临界日长的考虑.（）在选择时综合考虑在不育临界日长、不育临界 温度下的雄性不育度, 在诱导败育临界日长和可育临界温度下雄性可育度, 特别是 PE 与 TE 值的正与负、绝对值大小和两值之间的搭配或者说集成类型.

\section{3 合理设置栽培环境的光一温周期条件}

光敏性与温敏性的表现与否和表现强度受环境光-温周期条件的支配. 因此, 把待纯化的 不育系栽培在既适宜又稳定的光-温条件下, 确保光、温敏性充分、稳定地表现, 是育种家根据 表现型值识别不同基因型, 准确选择期望基因型的必要条件.

本文认为, 最好还是利用人工气候室. 只要光周期和温周期的设置合理, 动用 4 间人工气 候室, 再加上 2.2 所述的剥藮分株法, 不仅能够客观测量每一植株对光、温周期条件改变的应 答量—PEHT, PELT, TELD, TESD, 而且可以对该植株的不育临界温度、可育临界温度、不育临 界日长值及光敏温度区间的大小做出判断.

在实践中, 注意使光-温周期的设置尽量符合制种基地和繁种基地实际情况, 而且不过份 加大人工选择压, 例如不进一步降低关于不育临界低温的设置, 避免强化人工选择与自然选择 
的矛盾, 取得了满意的结果. 在北京的小区实验证明, 由培矮 $64 \mathrm{~s}$ 已经成功地分选出抽穗期晚 $7 \mathrm{~d}$ 栽培品系. 该品系经繁殖之后样本植株的花粉败育度合格, 不育性稳定, 整齐一致, 变异系

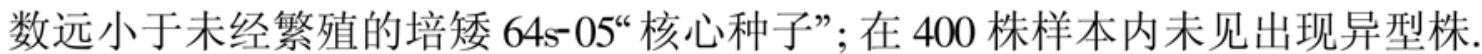

当然, 我国幅员辽阔, 生态条件极其形形色色. 应当充分利用现有雄性核不育水稻光敏性 与温敏性互作类型的遗传多样性, 有意识地分选适宜各生态区类型; 如何利用自然条件代替面 积十分有限的人工气候室, 如何利用 4 个或多个光-温周期条件各不相同的生态点做选择, 是 一个值得探索的问题.

1 石明松. 对光照长度敏感的隐性雄性不育水稻的发现与初步研究. 中国农业科学, 1985, 18(2)：44 48

2 袁隆平. 两系法杂交水稻研究进展. 中国农业科学, 1990, 23(1)：1 6

3 薛光行, 赵建宗. 水稻光敏感雄性不育临界日长及其对环境因子反应的初步研究. 作物学报, 1990, 16(2)：112 122

4 袁隆平. 选育水稻光、温敏核不育系的技术策略. 杂交水稻, 1992(1)：1 4

5 卢兴桂. 对水稻光、温敏雄性不育系选育中的一些问题的思考. 高技术通讯，1992(5)：1 4

6 刘建宾, 周承恕. 注重光温敏核不育系种子的标准化管理和原种生产. 杂交水稻, 1995(4)：18

7 袁隆平. 水稻光、温敏不育系的提纯和原种生产. 杂交水稻, 1994(6): 1 3

8 周广洽. 温敏核不育水稻的光温生态生理学. 长沙: 湖南师范大学出版社, 1996. 3 66

9 廖伏明, 袁隆平. 水稻光温敏核不育系起点温度遗传纯化的策略探讨. 杂交水稻, 1996(6)：1 4

10 周承恕,刘建宾. 利用海南春季低温条件提纯水稻低温敏核不育系. 杂交水稻, 1996( 5)：32

11 王长义, 威华雄, 胡 刚, 等. 粳稻光敏核不育系 N5088s 的原种生产与防杂保纯. 杂交水稻, 1995( 4)：16 18

12 李成荃, 王守海, 罗彦长, 等. 两系杂交粳稻育种及其种子产业. 见: 种子工程与农业发展. 北京: 中国农业出版社, 1997. 231 236 术出版社, 1995. 89 180 Geneva, 1996, 37 50 学报, $1998,25(2): 123 \sim 130$

薛光行. 试议光敏核不育水稻的异质性. 中国农学通报, 1996, 12(4)：31 33

Wallase D H. Physiological genetics of plant maturity, adaptation and yield. Plant Breed Rev, 1985, 3: 21 161

Salisbury F B, Ross C W. Plant Physiology, 3rd ed. California: A Division of Wadsworth Publishing Company, 1987. 428 430

Balzer I, Hardeland R. Thermophotoperiodism. In: Greppin H, Agosti R D, Bonzon M, ed. Vistas on Biorhythmicity. Genera: Univ

冯 亮. 光与植物的生长发育. 见: 刘良式等编著, 植物分子遗传学. 北京: 科学出版社, 1997, 452 495

Weigel D. The Genetics of flower development: from floral induction to ovule morphogenesis. Ann Rev Genetics, 1995, 29: 19 39

薛光行, 邓景扬. 雄性核不育水稻育性转换的光周期效应指数值 $(\mathrm{PE})$ 和温度效应指数值 $(\mathrm{TE})$ 的遗传性初步研究. 遗传

童 哲. 光敏核不育水稻的发育生物学研究评述. 植物学报, 1998, 40(3)：189 199

薛光行. 光敏核不育水稻温敏性 5 种表现型的识别. 中国农学通报, 1998，14(2)：26 28

肖翊华. 光敏核不育水稻的生理生化基础. 李泽炳主编, 光敏核不育水稻育性转换机理与应用研究. 武汉: 湖北科学技

白克智. 对水稻“光敏”、“温敏”雄性不育的一些看法和建议. 中国水稻科学, 1991，5(4)：137 138

孙宗修,程式华. 杂交水稻育种从三系、两系到一系. 北京: 中国农业科技出版社, 1994. 162

薛光行, 申岳正. 光周期条件对水稻光敏不育温度效应值影响的观察. 应用生态学报, 1997, 7( 1): 17 20

薛光行, 申岳正. 试议光敏不育水稻育性转换的光温作用模式. 作物学报, 1995, 21(2)：198 203 